University of Wollongong

Research Online

Faculty of Engineering and Information

Faculty of Engineering and Information

Sciences - Papers: Part A

Sciences

2014

Relating rejection of trace organic contaminants to membrane properties in forward osmosis: measurements, modelling and implications

Ming Xie

University of Wollongong, mx504@uowmail.edu.au

Long D. Nghiem

University of Wollongong, longn@uow.edu.au

William E. Price

University of Wollongong, wprice@uow.edu.au

Menachem Elimelech

Yale University

Follow this and additional works at: https://ro.uow.edu.au/eispapers

Part of the Engineering Commons, and the Science and Technology Studies Commons

Research Online is the open access institutional repository for the University of Wollongong. For further information contact the UOW Library: research-pubs@uow.edu.au 


\title{
Relating rejection of trace organic contaminants to membrane properties in forward osmosis: measurements, modelling and implications
}

\begin{abstract}
This study elucidates the relationship between membrane properties and the rejection of trace organic contaminants (TrOCs) in forward osmosis (FO). An asymmetric cellulose triacetate (CTA) and a thin-film composite (TFC) polyamide FO membrane were used for this investigation. The effective average pore radius (rp), selective barrier thickness over porosity parameter $(I / \varepsilon)$, surface charge, support layer structural parameter $(S)$, pure water permeability coefficient $(A)$ and salt $(\mathrm{NaCl})$ permeability coefficient (B) of the two membranes were systematically characterised. Results show that measured rejection of TrOCs as a function of permeate water flux can be well described by the pore hindrance transport model. This observation represents the first successful application of this model, which was developed for pressure-driven nanofiltration, to an osmotically-driven membrane process. The rejection of charged TrOCs by the CTA and TFC membranes was high and was governed by both electrostatic repulsion and steric hindrance. The TFC membrane exhibited higher rejection of neutral TrOCs with low molecular weight than the CTA membrane, although the estimated pore size of the TFC membrane $(0.42 \mathrm{~nm})$ was slightly larger than that of the CTA membrane $(0.37 \mathrm{~nm})$. This higher rejection of neutral TrOCs by the TFC membrane is likely attributed to its active layer properties, namely a more effective active layer structure, as indicated by a larger $\mathrm{I} / \varepsilon$ parameter, and pore hydration induced by the negative surface charge.
\end{abstract}

\section{Keywords}

trace, organic, contaminants, membrane, osmosis, measurements, properties, forward, relating, modelling, implications, rejection

\section{Disciplines \\ Engineering | Science and Technology Studies}

\section{Publication Details}

Xie, M., Nghiem, L. D., Price, W. E. \& Elimelech, M. (2014). Relating rejection of trace organic contaminants to membrane properties in forward osmosis: measurements, modelling and implications. Water Research, 49 (February), 265-274. 


\section{Relating rejection of trace organic contaminants to membrane properties in forward osmosis: measurements, modelling and implications}

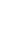

Water Research

Revised: $17^{\text {th }}$ November 2013

Ming Xie ${ }^{1}$, Long D. Nghiem ${ }^{1, *}$, William E. Price ${ }^{2}$, and Menachem Elimelech ${ }^{3}$

${ }^{1}$ Strategic Water Infrastructure Laboratory, School of Civil, Mining and Environmental Engineering, University of Wollongong, Wollongong, NSW 2522,

Australia

12 Strategic Water Infrastructure Laboratory, School of Chemistry, University of 2 Wollongong, Wollongong, NSW 2522, Australia

$3{ }^{3}$ Department of Chemical and Environmental Engineering, Yale University, New 4 Haven, CT 06520-8286, USA

16 * Corresponding author: Long Duc Nghiem, Email: longn@uow.edu.au; Ph +61 242214590 


\section{Abstract}

18 This study elucidates the relationship between membrane properties and the rejection 19 of trace organic contaminants (TrOCs) in forward osmosis (FO). An asymmetric cellulose 20 triacetate (CTA) and a thin-film composite (TFC) polyamide FO membrane were used for 21 this investigation. The effective average pore radius $\left(r_{p}\right)$, selective barrier thickness over 22 porosity parameter $(l / \varepsilon)$, surface charge, support layer structural parameter $(S)$, pure water 23 permeability coefficient $(A)$ and salt $(\mathrm{NaCl})$ permeability coefficient $(B)$ of the two 24 membranes were systematically characterised. Results show that measured rejection of 25 TrOCs as a function of permeate water flux can be well described by the pore hindrance 26 transport model. This observation represents the first successful application of this model, 27 which was developed for pressure-driven nanofiltration, to an osmotically-driven membrane 28 process. The rejection of charged TrOCs by the CTA and TFC membranes was high and was 29 governed by both electrostatic repulsion and steric hindrance. The TFC membrane exhibited 30 higher rejection of neutral TrOCs with low molecular weight than the CTA membrane, 31 although the estimated pore size of the TFC membrane $(0.42 \mathrm{~nm})$ was slightly larger than that 32 of the CTA membrane $(0.37 \mathrm{~nm})$. This higher rejection of neutral TrOCs by the TFC 33 membrane is likely attributed to its active layer properties, namely a more effective active 34 layer structure, as indicated by a larger $l / \varepsilon$ parameter, and pore hydration induced by the 35 negative surface charge.

36 Keywords: forward osmosis; solute rejection, membrane surface charge; trace organic 37 contaminants (TrOCs); permeate flux; pore hindrance transport model; pore size. 


\section{1. Introduction}

More than four billion people live in areas where drinking water security and ecosystem biodiversity are being threatened by freshwater shortages. This problem is being exacerbated by urbanization, population growth and climate change (Grant et al. 2012). As a result, significant research efforts have been made to facilitate the extraction of clean water from unconventional resources, such as seawater and wastewater effluent, to augment drinking water supplies. Membrane filtration processes, such as reverse osmosis (RO) and nanofiltration (NF), have contributed to a remarkable increase in the utilisation of unconventional water resources (Elimelech and Phillip 2011, Shannon et al. 2008). However, numerous trace organic contaminants (TrOCs) are being frequently detected in wastewater and sewage-impacted water bodies (Basile et al. 2011, Carballa et al. 2004, Schwarzenbach et al. 2006, Snyder et al. 2003 ). As a result, in addition to existing membrane processes such as $\mathrm{NF}$ and RO, novel treatment technologies, which can potentially provide a more efficient and cost-effective barrier against TrOCs, have also been explored.

Forward osmosis (FO) is one such novel membrane process that has the potential to advance water and wastewater treatment (Cath et al. 2006, Zhao et al. 2012). In FO, a semipermeable membrane is placed between a feed solution and a concentrated draw solution with high osmotic pressure. The extraction of water is driven by the osmotic pressure difference and, at the same time, salt and contaminants in the feed solution are being rejected by the FO membrane. To produce freshwater, FO is usually combined with pressure-driven membrane processes, such as NF and RO (Hoover et al. 2011, Shaffer et al. 2012, YangaliQuintanilla et al. 2011), or thermal processes, such as conventional column distillation (McCutcheon et al. 2005, McGinnis and Elimelech 2007) and membrane distillation (Cath et al. 2005, Martinetti et al. 2009). In these hybrid treatment systems, TrOCs in the feed are first subjected to rejection by the FO membrane and then by the subsequent process that is used to both concentrate the draw solution and produce freshwater, thereby providing a dual barrier for TrOCs. Hence, it is of paramount importance to better elucidate the removal of TrOCs in the FO process.

High removal efficiency of TrOCs by the FO process has been demonstrated in several previous studies. Cartinella et al. (2006) found a near complete rejection of three hormones in FO. Cath et al. (2010) reported the rejection of six TrOCs, ranging from $72 \%$ (salicylic acid) to more than $99 \%$ (diclofenac). A comprehensive study on the removal of 23 TrOCs revealed that the rejection of charged TrOCs was consistently above $80 \%$, whereas the 
72 rejection of neutral TrOCs varied from 40 to $90 \%$ (Hancock et al. 2011b). A similar 73 observation was also reported by Valladares Linares et al (2011) when examining the removal of 13 TrOCs. Alturki et al. (2013) elucidated the mechanisms governing the rejection of 40 TrOCs compounds by FO, indicating that the rejection of charged TrOCs is governed by both electrostatic interaction and size exclusion, while rejection of neutral compounds is dominated by size exclusion.

It is noteworthy that to date most studies investigating the removal of TrOCs by the FO process employed an asymmetric cellulose triacetate (CTA) membrane. Given the recent progress in the development of new membrane materials for FO applications, polyamide thinfilm composite (TFC) membranes have been recently introduced. These TFC membranes have been reported to have higher water permeability and solute rejection compared to their CTA counterparts (Wang et al. 2010, Wei et al. 2011, Yip et al. 2010). Because there are considerable differences between asymmetric CTA and polyamide TFC membranes, it is worthwhile to systematically examine their rejection performance and provide insights into the relationship between membrane properties and TrOCs rejection.

In this study, we examine and compare the rejection of 12 TrOCs by an asymmetric CTA and a polyamide TFC membrane as a function of permeate water flux. Key properties of the CTA and TFC membranes were characterised to facilitate the understanding of their

90 TrOC rejection behaviour. The membrane pore hindrance transport model was used to predict the rejection of the TrOCs as a function of permeate water flux and model predictions were compared with the experimentally measured data. Rejection of TrOCs by the CTA and TFC membranes was related to the membrane properties and mechanisms responsible for the rejection of TrOCs were proposed and elucidated.

\section{2. Materials and methods}

\subsection{Trace organic contaminants}

Twelve TrOCs, frequently detected in secondary treated effluent and sewage-impacted water bodies at trace levels, were used for this investigation. The TrOCs were selected to cover a diverse range of properties including charge, hydrophobicity and molecular weight

100 (Table 1). A combined stock solution containing $1 \mathrm{~g} / \mathrm{L}$ of each TrOC was prepared in 101 methanol. The stock solution was kept at $-18^{\circ} \mathrm{C}$ in the dark and was used within one month. 
104 A bench-scale FO system consisting of a cross-flow membrane cell with a total 105 effective membrane area of $123.5 \mathrm{~cm}^{2}$ was employed. The membrane cell had two identical 106 and symmetrical flow chambers with length, width and channel height of 130, 95, and $2 \mathrm{~mm}$, 107 respectively. The circulation flow rates of the feed and draw solutions were kept constant at 1 $108 \mathrm{~L} / \mathrm{min}$ (corresponding to a cross flow velocity of $9 \mathrm{~cm} / \mathrm{s}$ ). The draw solution reservoir was 109 placed on a digital balance (Mettler Toledo Inc., Hightstown, NJ) and weight changes were 110 recorded by a computer to calculate the permeate water flux. A conductivity controller (Cole-

111 Parmer, Vernon Hills, IL) was used to maintain a constant draw solution concentration when 112 inorganic salt was used as the draw solute. Further details of this conductivity control system 113 are available elsewhere (Xie et al. 2012a).

114 A bench-scale RO system with a rectangular stainless-steel cross-flow cell was used to 115 characterise the membrane pore radius and membrane transport parameters. The RO 116 membrane cell had an effective membrane area of $40 \mathrm{~cm}^{2}$, with channel length, width and 117 depth of 100, 40 and $2 \mathrm{~mm}$, respectively. The unit was equipped with a Hydra-Cell pump 118 (Wanner Engineering Inc., Minneapolis, MN). The temperature of the feed solution was kept 119 constant using a chiller/heater (Neslab RTE 7). Permeate flow was measured by a digital flow 120 meter (FlowCal 5000, Tovatech, South Orange, NJ).

\section{2.3. Characterization of forward osmosis membranes}

122 An asymmetric CTA and a polyamide TFC membrane were acquired from Hydration 123 Technology Innovations (Albany, OR) and Oasys Water (Boston, MA), respectively. The 124 CTA membrane is composed of a cellulose triacetate layer with an embedded woven support 125 mesh (Cath et al. 2006, McCutcheon and Elimelech 2008). The TFC membrane is made of a 126 thin selective polyamide active layer on top of a porous polysulfone support layer (Cath et al. 127 2013, McGinnis et al. 2013) .

\section{$128 \quad$ 2.3.1 Membrane transport parameters}

129 Key membrane transport parameters were characterised following the protocol 130 previously described by Cath et al. (2013), including pure water permeability coefficient of 131 the active layer, $A$, the salt $(\mathrm{NaCl})$ permeability coefficient of the active layer, $B$, and the 132 structural parameter of the support layer, $S$. Briefly, the membrane $A$ and $B$ values were 133 determined using the RO cross-flow filtration system (section 2.2). The membrane $A$ value 
134 was measured at a pressure of 10 bar using deionised water. $\mathrm{NaCl}$ was then added to the feed 135 solution to determine the $B$ value. The RO system was stabilised for two hours before 136 recording permeate water flux with $2000 \mathrm{mg} / \mathrm{L} \mathrm{NaCl}$ solution, $J_{w}^{\mathrm{NaCl}}$, and taking feed and permeate samples to determine the observed $\mathrm{NaCl}$ rejection, $R_{\mathrm{o}}$. Membrane The membrane $A$

138 value was calculated by dividing the pure water permeate flux $\left(J_{w}^{R O}\right)$ by the applied hydraulic 139 pressure, $\Delta P$ :

$$
A=J_{w}^{R O} / \Delta P
$$

141 The observed salt $(\mathrm{NaCl})$ rejection, $R_{0}$, was calculated from the difference between the 142 bulk feed $\left(c_{\mathrm{b}}\right)$ and permeate $\left(c_{\mathrm{p}}\right)$ salt concentrations, $R_{\mathrm{o}}=1-c_{\mathrm{p}} / c_{\mathrm{b}}$, and then the membrane $B$ 143 value was determined from:

$$
B=J_{w}^{N a C l}\left(\frac{1-R_{o}}{R_{o}}\right) \exp \left(-\frac{J_{w}^{N a C l}}{k_{f}}\right)
$$

where $k_{\mathrm{f}}$ is the mass transfer coefficient for the cross-flow of RO membrane cell.

The mass transfer coefficient $\left(k_{\mathrm{f}}\right)$ was experimentally determined using the Sutzkover et al. method (Sutzkover et al. 2000). Using the permeate and feed salt concentrations (and thus, the corresponding osmotic pressures based on van't Hoff equation, $\pi_{\mathrm{p}}$ and $\pi_{\mathrm{b}}$, respectively), the applied pressure $(\Delta \mathrm{P})$, the pure water flux $\left(J_{w}^{R O}\right)$, and the permeate flux with the $2000 \mathrm{mg} / \mathrm{L} \mathrm{NaCl}$ solution $\left(J_{w}^{\mathrm{NaCl}}\right)$ enabled the evaluation of the salt concentration at the membrane surface. This membrane surface concentration was used with thin-film theory for concentration polarization to determine $k_{\mathrm{f}}$ :

$$
k_{f}=\frac{J_{w}^{\mathrm{NaCl}}}{\ln \left[\frac{\Delta P}{\pi_{b}-\pi_{p}}\left(1-\frac{J_{w}^{\mathrm{NaCl}}}{J_{w}^{R O}}\right)\right]}
$$

The membrane structural parameter, $S$, was evaluated in the cross-flow FO setup 155 (section 2.2). The water flux, $J_{w}^{F O}$, using a $0.5 \mathrm{M} \mathrm{NaCl}$ draw solution and deionised water

156 feed solution was measured with the membrane in FO mode (i.e., active layer facing the feed 157 solution). The membrane $S$ value was determined using:

$$
S=\frac{D_{s}}{J_{w}^{F O}} \ln \left(\frac{B+A \pi_{D, b}}{B+J_{w}+A \pi_{F, m}}\right)
$$


159 where $D_{\mathrm{s}}$ is the bulk solution diffusivity of the draw solute, $\pi_{\mathrm{D}, \mathrm{b}}$ is the bulk osmotic pressure

160 of the draw solution, and $\pi_{\mathrm{F}, \mathrm{m}}$ is the osmotic pressure at the membrane surface on the feed 161 side (zero for deionised water feed). The values of $A$ and $B$ in Eq. 4 were calculated using 162 Eqs. 1 and 2.

\section{$163 \quad$ 2.3.2 Membrane average pore radius}

164 Erythritol, xylose, and glucose (Sigma-Aldrich, Saint Louis, MO) were used as the 165 reference organic solutes to estimate the membrane active layer effective pore size. The 166 solutes were individually dissolved in Milli-Q water to obtain a concentration of $40 \mathrm{mg} / \mathrm{L}$ (as total organic carbon (TOC)). Prior to the RO filtration experiments with these reference organic solutes, the membrane was pre-compacted at 18 bar for one hour and subsequent experiments were conducted at $8,10,12,14$, and 16 bar with a cross-flow velocity of $25 \mathrm{~cm} / \mathrm{s}$. At each pressure value, the RO filtration system was operated for one hour before taking permeate and feed samples for analysis.

The membrane average pore radius was determined based on the pore hindrance transport model previously described by Nghiem et al (2004) for nanofiltration. In this model, the FO membrane was considered as a bundle of cylindrical capillary tubes with the same radius. In addition, we assumed that the spherical solute particles enter the membrane pores in random fashion. It is noteworthy that the pore hindrance model was developed for neutral and non-adsorptive solutes. Thus, it may underestimate the rejection of charged organic compounds and overestimate the rejection of hydrophobic organic compounds.

In the pore hindrance transport model, the ratio of solute radius $\left(r_{\mathrm{s}}\right)$ to the membrane 180 pore radius $\left(r_{\mathrm{p}}\right), \lambda=r_{\mathrm{s}} / r_{\mathrm{p}}$, is related by the distribution coefficient $\varphi$ when only steric interactions are considered:

$$
\varphi=(1-\lambda)^{2}
$$

183 The real rejection of the reference organic solutes $\left(R_{r}\right)$ was determined from:

$$
R_{r}=1-\frac{c_{L}}{c_{o}}=1-\frac{\varphi K_{c}}{1-\exp \left(-P_{e}\right)\left(1-\varphi K_{c}\right)}
$$

185 where $c_{\mathrm{o}}$ and $c_{\mathrm{L}}$ are the solute concentration just outside the pore entrance and pore exit, 186 respectively; $\varphi$ is the distribution coefficient for hard-sphere particles when only steric 187 interactions are considered; $K_{\mathrm{c}}$ is the hydrodynamic hindrance coefficient for convection; and $188 P_{e}$ is the membrane Peclet number defined as: 


$$
P e=\frac{K_{c} J_{v} l}{K_{d} D \varepsilon}
$$

190 Here, $K_{\mathrm{d}}$ is the hydrodynamic hindrance coefficient for diffusion, $J_{\mathrm{v}}$ is the membrane 191 volumetric permeate flux, $D$ is the Stokes-Einstein diffusion coefficient, $l$ is the theoretical 192 pore length (i.e., active layer thickness), and $\varepsilon$ is the effective porosity of the membrane 193 active later. Details on the calculations of $P_{e}, K_{\mathrm{c}}$ and $K_{\mathrm{d}}$ are given elsewhere (Bungay and 194 Brenner 1973, Nghiem et al. 2004). The $\varphi K_{c}$ and $\varphi K_{d}$ are two hindrance factors accounting 195 for solute convection and diffusion, respectively. These factors are significantly dependent on $196 \lambda$, the ratio of solute radius $\left(r_{s}\right)$ to the membrane pore radius $\left(r_{p}\right)$.

197 The real rejection in Eq. 6 is linked to the observed rejection $R_{\mathrm{o}}$ using the film theory 198 which accounts for concentration polarization:

$$
\ln \frac{\left(1-R_{r}\right)}{R_{r}}=\ln \left(\frac{1-R_{o}}{R_{o}}\right)-\frac{J_{v}}{k_{f}}
$$

where $k_{f}$ is the mass transfer coefficient and $J_{v}$ is the water permeate flux.

\subsubsection{Membrane surface charge}

The zeta potential of the membrane surface was determined using a SurPASS electrokinetic analyser (Anton Paar GmbH, Graz, Austria). The value for each surface was calculated from the measured streaming potential using the Fairbrother-Mastin approach (Elimelech et al. 1994). All streaming potential measurements were conducted in a background electrolyte solution containing $10 \mathrm{mM} \mathrm{KCl}$. The same electrolyte solution was used to flush the cell thoroughly prior to $\mathrm{pH}$ titration using either hydrochloric acid $(1 \mathrm{M})$ or potassium hydroxide $(1 \mathrm{M})$. All measurements were performed at room temperature (approximately $22^{\circ} \mathrm{C}$ ).

\subsection{Trace organic contaminant rejection experiment}

The TrOC stock solution was added to a background electrolyte solution $(20 \mathrm{mM} \mathrm{NaCl}$

212 and $\left.1 \mathrm{mM} \mathrm{NaHCO}_{3}\right)$ to obtain a feed solution concentration of $2 \mu \mathrm{g} / \mathrm{L}$. Either $\mathrm{HCl}(1 \mathrm{M})$ or $213 \mathrm{NaOH}(1 \mathrm{M})$ was used to adjust the initial $\mathrm{pH}$ value of the feed solution.

214 In FO experiments, the initial volumes of the feed and draw solutions were 4 and $1 \mathrm{~L}$, 215 respectively. The feed and draw solutions were kept at $25 \pm 0.1{ }^{\circ} \mathrm{C}$ using a temperature 216 controller (Neslab RTE 7). A new FO membrane sample was used for each experiment, 
217 which was concluded when $1 \mathrm{~L}$ water had permeated through the FO membrane (i.e., 25\%

218 water recovery). The reverse solute flux of $\mathrm{NaCl}$ was determined using electric conductivity

219 measurements and an $\mathrm{NaCl}$ calibration curve. A $500 \mathrm{~mL}$ aliquot of sample from the feed and

220 draw solutions were taken at the beginning and after $1 \mathrm{~L}$ water had permeated through the FO

221 membrane for solid phase extraction (SPE) using Oasis HBL SPE cartridge and subsequent

222 liquid chromatography-mass spectrometry (LC-MS) analysis.

223 2.5. Analysis of trace organic contaminants

224 The TrOC concentrations in the feed and draw solution samples were determined by 225 liquid chromatography - mass spectrometry (LC-MS) using an electrospray ionization 226 interface. The analysis was conducted in selective ion monitoring mode using a Shimadzu 227 LC-MS 2020. Further details on the TrOC analytical method can be found in a previous 228 publication (Xie et al. 2013).

\section{3. Results and discussion}

\section{3.1. Membrane properties}

\section{$231 \quad 3.1 .1$ Transport parameters}

232 Transport parameters of the CTA and TFC membranes are summarized in Table 2. 233 The CTA membrane was found to have a lower pure water permeability coefficient ( $A$ value) 234 and a higher structural parameter ( $S$ value) than the TFC membrane. As a result, using a 0.5 $235 \mathrm{M} \mathrm{NaCl}$ draw solution and deionised water feed, the obtained average water fluxes of the 236 CTA and TFC membranes were 5.4 and $15.1 \mathrm{~L} / \mathrm{m}^{2} \mathrm{~h}$, respectively. Furthermore, the salt 237 ( NaCl) permeability coefficient of the CTA membrane was significantly higher than that of 238 the TFC membrane (Table 2). Consequently, the reverse $\mathrm{NaCl}$ flux of the CTA membrane $239\left(82.7 \mathrm{mmol} / \mathrm{m}^{2} \mathrm{~h}\right)$ was one order of magnitude higher than that for the TFC membrane $(5.5$ $240 \mathrm{mmol} / \mathrm{m}^{2} \mathrm{~h}$ ) under the same operating conditions.

\section{[Table 2]}

242

\subsubsection{Surface charge}

Zeta potential measurements suggested that the surface of the TFC membrane was significantly more negatively charged than that of the CTA membrane at an experimental $\mathrm{pH}$ of 6.5 (Figure 1). The highly negatively charged surface of the TFC membrane can be attributed to the dissociation of free or uncross-linked carboxylic functional groups of the 
polyamide active skin layer (Petersen 1993). On the other hand, the predominant functional

248 group on the CTA membrane surface is hydroxyl (Mi and Elimelech 2010), which can only be deprotonated at high $\mathrm{pH}$. Tiraferri and Elimelech (2012) measured the distribution of negatively charged functional groups of the CTA membrane using the toluidine blue $\mathrm{O}$ method and reported that the number of negatively charged functional groups was negligible. Indeed, the marginal negative charge of the CTA membrane observed in Figure 1 can be attributed to preferential adsorption of anions, such as chloride and hydroxide, onto the membrane surface (Childress and Elimelech 1996, Elimelech and O'Melia 1990).

\subsubsection{Average pore radius and active layer structure}

Real rejection $\left(R_{r}\right)$ of each reference organic solute was determined from observed rejection $\left(R_{o}\right)$ by accounting for concentration polarization effects using Eq. 7 and the mass transfer coefficient calculated from Eq. 3. The real rejections obtained at different permeate fluxes were used to calculate the membrane average membrane pore size based on the membrane pore hindrance transport model presented earlier (Eq. 6). The parameters $\varphi K_{c}$ and $P_{e} / J_{v}$ are uniquely related to $R_{r}$. Thus, they could be determined by fitting the reference organic solute rejection data to the model (Eq. 6) using an optimization procedure (Solver, Microsoft Excel). Because the parameters $\varphi K_{c}$ and $P_{e} / J_{\mathrm{v}}$ can be expressed as a sole function of the variable $\lambda$ (which is the ratio of solute radius $\left(r_{s}\right)$ to membrane pore radius $\left(r_{p}\right)$ ), $\lambda$ can be obtained for each reference organic solute and the membrane. The membrane average pore radius was then calculated for each reference solute rejection data. The membrane active layer structure indicated by the $l / \varepsilon$ value could also be determined from the values of $\varphi K_{c}$, $P_{e} / J_{\mathrm{v}}$, and the diffusion coefficient of the reference organic solute. The obtained average pore radii and the $l / \varepsilon$ values of each membrane are shown in Table 3.

\section{[Table 3]}

For each membrane, the pore radii obtained from the three reference organic solutes only slightly deviate from one to another. Results reported in Table 3 show that the average pore radius of the CTA membrane is smaller than that of the TFC membrane. In general agreement with their comparative average pore size, the CTA membrane had a smaller water permeability coefficient (Table 2) and a lower reverse draw solute flux (Table 4) in comparison to the TFC membrane when $\mathrm{MgSO}_{4}$ or glucose was used as draw solute. On the 
279 order of magnitude higher than that of the CTA membrane (Table 3). This significant 280 difference in the active layer structure could result in a higher hindrance to solute transport by 281 the TFC membrane compared to the CTA membrane (Nghiem et al. 2004, Schäfer et al. 282 2011). In addition, the TFC membrane pores are hydrated due to the existence of charged 283 functional groups within its polyamide active layer (Raghunathan and Aluru 2006). Such 284 adsorption of water molecules within the membrane pore (i.e., the hydration of the membrane 285 pore) could narrow the effective membrane pore size, thereby enhancing the solute hindrance. 286 As a result, both the active layer structure and pore hydration likely play an important role in 287 feed solute transport through the membrane. Indeed, the TFC membrane active layer with 288 higher solute hindrance and narrowed membrane pore exhibited better separation 289 performance (i.e., lower $B$ value and reverse $\mathrm{NaCl}$ flux) compared with the CTA membrane. 290 This hypothesis will be further examined by comparing the rejection of TrOCs by the CTA 291 and TFC membranes in the following section.

\section{[Table 4]}

\subsection{Rejection of trace organic contaminants}

\subsubsection{General behaviour}

Observed rejections of charged and neutral TrOCs by either the CTA or TFC membranes were markedly different for FO experiments at the same permeate water flux of 6 $\mathrm{L} / \mathrm{m}^{2} \mathrm{~h}$ (or $1.68 \mu \mathrm{m} / \mathrm{s}$ ) (Figure 2). Although the chemistry and intrinsic properties of the CTA and TFC membranes are different, rejection of charged TrOCs by both membranes were generally higher than those of neutral TrOCs, which is consistent with previous studies (Alturki et al. 2013, Valladares Linares et al. 2011, Xie et al. 2012b). These charged TrOCs may be rejected by both size exclusion and electrostatic repulsion arising from their hydrated molecular dimension and the negative surface charge of the membranes. On the other hand, 303 there was no discernible difference in the rejection of charged TrOCs by the two membranes. 304 Further, the TFC membrane exhibited substantially higher rejection of neutral TrOCs than the 305 CTA membrane, despite its larger membrane pore size (Table 3). This observation was consistent with our hypothesis proposed in section 3.1.3 that the hydrated membrane pore surface induced by the existence of surface charge narrowed the effective membrane pore size, thereby enhancing the steric hindrance and resulting in better separation performance.

309 This hypothesis will be further elaborated using the membrane pore hindrance transport

310 model for a wide range of permeate water flux values in the following section. 


\section{3.2.2 Modelling the rejection of trace organic contaminants}

313 The calculated membrane pore radii (Table 3) and the molecular radius of each 314 compound can be used to simulate the rejection of TrOCs as a function of permeate water

315 flux based on the membrane pore hindrance transport model (see section 2.3.2). This model

316 was found to describe very well the real rejection of TrOCs by both the CTA and TFC 317 membranes. Overall, the real rejection of TrOCs by both membranes increased as permeate 318 flux increased, consistent with the phenomenon observed in pressure driven NF and RO 319 processes (Nghiem et al. 2004).

320 Real rejections of charged TrOCs were above 90\% for both CTA and TFC 321 membranes (Figure 3). For negatively charged TrOCs, electrostatic repulsion arising from the 322 negative surface charge of the membranes played an important role in their rejection. For 323 example, despite similar molecular weight of sulfamethoxazole and linuron, real rejection of 324 the negatively charged sulfamethoxazole $(0.90$ by the CTA membrane and 0.98 by the TFC 325 membrane) was substantially higher than the neutral linuron ( 0.59 by the CTA membrane and 3260.82 by the TFC membrane). More significantly, there was marginal difference in real 327 rejection of negatively charged TrOCs as their molecular weight increased. In aqueous 328 solution, the charged TrOCs are hydrated and their hydrated radii are significantly larger than 329 their apparent ionic radii (Nghiem et al. 2006). As a result, steric hindrance also governs the 330 separation of both negatively and positively charged TrOCs. In summary, both electrostatic 331 repulsion and steric hindrance govern the rejection of charged TrOCs in FO, thereby resulting 332 in their high rejection.

333 Generally, the TFC membrane exhibited higher rejection of hydrophilic neutral 334 (caffeine and atrazine) and hydrophobic neutral (linuron and pentachlorophenol) TrOCs with 335 low molecular weights (Figure 4). As the molecular weight increased, there was no 336 discernible difference in the rejection of neutral hydrophilic and hydrophobic TrOCs by 337 either the CTA or TFC membranes. This molecular-weight dependent rejection behaviour 338 suggests that steric hindrance governs the rejection of neutral TrOCs in an FO process. 339 However, it is noteworthy that despite its larger effective pore size compared to that of the 340 CTA membrane, the TFC membrane exhibited higher rejection of neutral TrOCs with low 341 molecular weight than the CTA membrane. 


\section{$344 \quad 3.2 .3$ Relating trace organic rejection to membrane properties}

345 Structure of the membrane active layer plays an important role in the rejection of TrOCs. 346 Active layer structures of the CTA and TFC membranes differed significantly. The TFC 347 membrane has a higher $l / \varepsilon$ parameter and thus exhibits higher hindrance to TrOC diffusion in 348 comparison to the CTA membrane. The higher solute hindrance of the TFC membrane is also 349 consistent with its lower $B$ value, which can be described by the "solution-diffusion" 350 mechanism in the FO process (Hancock et al. 2011a, Yong et al. 2012).

351 Pore hydration induced by membrane surface charge also attributed to the higher TrOC rejection by the TFC membrane. Pore hydration exists in both the CTA and TFC membranes, which is manifested by a layer of water molecules permanently attached to the negatively charged membrane surface via hydrogen bonding (Raghunathan and Aluru 2006). However, the degrees of pore hydration of the CTA and TFC membranes were likely different when they are operated in $\mathrm{FO}$ mode because of the difference in reverse $\mathrm{NaCl}$ permeation (Figure 5). Specifically, the CTA membrane possessed less surface charge (Figure 1) and exhibited an order of magnitude higher reverse $\mathrm{NaCl}$ flux than the TFC membrane (Table 4). Thus, pore hydration of the CTA membrane was substantially suppressed due to the elevated ionic strength in the membrane pore (Nghiem et al. 2006). By contrast, the TFC membrane has a much lower reverse $\mathrm{NaCl}$ salt flux due to a more negative membrane surface charge in comparison to the CTA membrane. Thus, TFC membrane pores remain highly hydrated in FO mode, resulting in a higher TrOC rejection when compared to the CTA membrane.

Results reported here have significant implications for the fabrication of next generation FO membranes. The separation performance of FO membranes could be improved substantially by tuning both the active layer structure and surface charge. Fabricating an active layer with superior transport properties is important in achieving better TrOC rejections (Tiraferri et al. 2011), such as high $A$ and low $B$ values, and high $l / \varepsilon$ value. Imparting surface charge to the membrane could offer enhanced steric hindrance without compromising water diffusion. In a recent study, Flanagan and Escobar (2013) modified a neutral polybenzimidazole based membrane using different functional agents to impart negative surface charges and reported higher water flux and $\mathrm{NaCl}$ rejection than unmodified

374 PBI membrane. However, the possible detrimental effects of carboxyl groups on the 
membrane resistance to organic fouling should be considered (Mo et al. 2012), which requires optimization of charge density and type of functional groups.

\section{Conclusions}

We have systematically characterised key properties of the CTA and TFC membranes and compared their rejection of $12 \mathrm{TrOCs}$ as a function of permeate flux using the membrane pore hindrance transport model. The TFC membrane has a higher $A$ value, lower $B$ and $S$ values and higher surface charge than those of the CTA membrane. As a result, the TFC membrane exhibited a higher water flux and lower reverse $\mathrm{NaCl}$ flux than the CTA membrane. More importantly, the calculated membrane pore radii of the CTA and TFC membranes were 0.37 and $0.42 \mathrm{~nm}$, respectively. The calculated active layer structure factor, $l / \varepsilon$, of the CTA and TFC membranes were 0.11 and $2.12 \mu \mathrm{m}$, respectively.

386 The pore hindrance transport model can be used to describe the rejection of TrOCs by the FO process. Rejection of charged TrOCs by both the CTA and TFC membranes was generally high and was governed by both electrostatic interaction and steric hindrance. In contrast, the TFC membrane exhibited higher rejection of neutral TrOCs with low molecular weight than the CTA membrane, albeit that the TFC membrane pore size was larger than that for the CTA membrane. We attribute the observed higher rejection of neutral TrOCs by the TFC membrane to a more favourable active layer structure as indicated by the larger active layer thickness to porosity ratio parameter, $l / \varepsilon$, and the negative membrane surface charge that induced pore hydration.

\section{Acknowledgements}

The authors would like to thank Hydration Technology Innovations and Oasys Water for providing membrane samples. University of Wollongong is acknowledged for the provision of a doctoral scholarship to Ming Xie.

\section{References}

400 Alturki, A.A., McDonald, J.A., Khan, S.J., Price, W.E., Nghiem, L.D. and Elimelech, M. 401 (2013) Removal of trace organic contaminants by the forward osmosis process. Separation 402 and Purification Technology 103, 258-266.

403 Basile, T., Petrella, A., Petrella, M., Boghetich, G., Petruzzelli, V., Colasuonno, S. and 404 Petruzzelli, D. (2011) Review of Endocrine-Disrupting-Compound Removal Technologies in 405 Water and Wastewater Treatment Plants: An EU Perspective. Industrial \& Engineering 406 Chemistry Research 50(14), 8389-8401. 
407 Bungay, P.M. and Brenner, H. (1973) The motion of a closely-fitting sphere in a fluid-filled 408 tube. International Journal of Multiphase Flow 1(1), 25-56.

409 Carballa, M., Omil, F., Lema, J.M., Llompart, M.a., García-Jares, C., Rodríguez, I., Gómez, 410 M. and Ternes, T. (2004) Behavior of pharmaceuticals, cosmetics and hormones in a sewage 411 treatment plant. Water Research 38(12), 2918-2926.

412 Cartinella, J.L., Cath, T.Y., Flynn, M.T., Miller, G.C., Hunter, K.W. and Childress, A.E. 413 (2006) Removal of Natural Steroid Hormones from Wastewater Using Membrane Contactor 414 Processes†. Environmental Science \& Technology 40(23), 7381-7386.

415 Cath, T.Y., Adams, D. and Childress, A.E. (2005) Membrane contactor processes for 416 wastewater reclamation in space: II. Combined direct osmosis, osmotic distillation, and 417 membrane distillation for treatment of metabolic wastewater. Journal of Membrane Science 418 257(1-2), 111-119.

419 Cath, T.Y., Childress, A.E. and Elimelech, M. (2006) Forward osmosis: Principles, 420 applications, and recent developments. Journal of Membrane Science 281(1-2), 70-87.

421 Cath, T.Y., Elimelech, M., McCutcheon, J.R., McGinnis, R.L., Achilli, A., Anastasio, D., 422 Brady, A.R., Childress, A.E., Farr, I.V., Hancock, N.T., Lampi, J., Nghiem, L.D., Xie, M. 423 and Yip, N.Y. (2013) Standard Methodology for Evaluating Membrane Performance in 424 Osmotically Driven Membrane Processes. Desalination 312, 31-38.

425 Cath, T.Y., Hancock, N.T., Lundin, C.D., Hoppe-Jones, C. and Drewes, J.E. (2010) A multi426 barrier osmotic dilution process for simultaneous desalination and purification of impaired 427 water. Journal of Membrane Science 362(1-2), 417-426.

428 Childress, A.E. and Elimelech, M. (1996) Effect of solution chemistry on the surface charge 429 of polymeric reverse osmosis and nanofiltration membranes. Journal of Membrane Science 430 119(2), 253-268.

431 Elimelech, M., Chen, W.H. and Waypa, J.J. (1994) Measuring the zeta (electrokinetic) 432 potential of reverse osmosis membranes by a streaming potential analyzer. Desalination 95(3), $433269-286$.

434 Elimelech, M. and O'Melia, C.R. (1990) Effect of electrolyte type on the electrophoretic 435 mobility of polystyrene latex colloids. Colloids and Surfaces 44, 165-178.

436 Elimelech, M. and Phillip, W.A. (2011) The Future of Seawater Desalination: Energy, 437 Technology, and the Environment. Science 333(6043), 712-717.

438 Flanagan, M.F. and Escobar, I.C. (2013) Novel Charged and Hydrophilized 439 Polybenzimidazole (PBI) Membranes for Forward Osmosis. Journal of Membrane Science $440 \quad 434,85-92$.

441 Grant, S.B., Saphores, J.-D., Feldman, D.L., Hamilton, A.J., Fletcher, T.D., Cook, P.L.M., 442 Stewardson, M., Sanders, B.F., Levin, L.A., Ambrose, R.F., Deletic, A., Brown, R., Jiang, 443 S.C., Rosso, D., Cooper, W.J. and Marusic, I. (2012) Taking the "Waste" Out of "Wastewater" 444 for Human Water Security and Ecosystem Sustainability. Science 337(6095), 681-686.

445 Hancock, N.T., Phillip, W.A., Elimelech, M. and Cath, T.Y. (2011a) Bidirectional 446 Permeation of Electrolytes in Osmotically Driven Membrane Processes. Environmental 447 Science \& Technology 45(24), 10642-10651.

448 Hancock, N.T., Xu, P., Heil, D.M., Bellona, C. and Cath, T.Y. (2011b) Comprehensive 449 Bench- and Pilot-Scale Investigation of Trace Organic Compounds Rejection by Forward 450 Osmosis. Environmental Science \& Technology 45(19), 8483-8490. 
451 Hoover, L.A., Phillip, W.A., Tiraferri, A., Yip, N.Y. and Elimelech, M. (2011) Forward with

452 Osmosis: Emerging Applications for Greater Sustainability. Environmental Science \& 453 Technology 45(23), 9824-9830.

454 Martinetti, C.R., Childress, A.E. and Cath, T.Y. (2009) High recovery of concentrated RO 455 brines using forward osmosis and membrane distillation. Journal of Membrane Science 456 331(1-2), 31-39.

457 McCutcheon, J.R. and Elimelech, M. (2008) Influence of membrane support layer 458 hydrophobicity on water flux in osmotically driven membrane processes. Journal of 459 Membrane Science 318(1-2), 458-466.

460 McCutcheon, J.R., McGinnis, R.L. and Elimelech, M. (2005) A novel ammonia - carbon 461 dioxide forward (direct) osmosis desalination process. Desalination 174(1), 1-11.

462 McGinnis, R.L. and Elimelech, M. (2007) Energy requirements of ammonia-carbon dioxide 463 forward osmosis desalination. Desalination 207(1-3), 370-382.

464 McGinnis, R.L., Hancock, N.T., Nowosielski-Slepowron, M.S. and McGurgan, G.D. (2013)

465 Pilot demonstration of the $\mathrm{NH}_{3} / \mathrm{CO}_{2}$ forward osmosis desalination process on high salinity 466 brines. Desalination 312, 67-74.

467 Mi, B. and Elimelech, M. (2010) Gypsum Scaling and Cleaning in Forward Osmosis: 468 Measurements and Mechanisms. Environmental Science \& Technology 44(6), 2022-2028.

469 Mo, Y., Tiraferri, A., Yip, N.Y., Adout, A., Huang, X. and Elimelech, M. (2012) Improved 470 Antifouling Properties of Polyamide Nanofiltration Membranes by Reducing the Density of 471 Surface Carboxyl Groups. Environmental Science \& Technology 46(24), 13253-13261.

472 Nghiem, L.D., Schafer, A.I. and Elimelech, M. (2006) Role of electrostatic interactions in the 473 retention of pharmaceutically active contaminants by a loose nanofiltration membrane. 474 Journal of Membrane Science 286(1-2), 52-59.

475 Nghiem, L.D., Schäfer, A.I. and Elimelech, M. (2004) Removal of Natural Hormones by 476 Nanofiltration Membranes: Measurement, Modeling, and Mechanisms. Environmental 477 Science \& Technology 38(6), 1888-1896.

478 Petersen, R.J. (1993) Composite reverse osmosis and nanofiltration membranes. Journal of 479 Membrane Science 83(1), 81-150.

480 Raghunathan, A.V. and Aluru, N.R. (2006) Molecular Understanding of Osmosis in 481 Semipermeable Membranes. Physical Review Letters 97(2), 024501.

482 Schäfer, A.I., Akanyeti, I. and Semião, A.J.C. (2011) Micropollutant sorption to membrane 483 polymers: A review of mechanisms for estrogens. Advances in Colloid and Interface Science 484 164(1-2), 100-117.

485 Schwarzenbach, R.P., Escher, B.I., Fenner, K., Hofstetter, T.B., Johnson, C.A., von Gunten, 486 U. and Wehrli, B. (2006) The Challenge of Micropollutants in Aquatic Systems. Science 487 313(5790), 1072-1077.

488 Shaffer, D.L., Yip, N.Y., Gilron, J. and Elimelech, M. (2012) Seawater desalination for 489 agriculture by integrated forward and reverse osmosis: Improved product water quality for 490 potentially less energy. Journal of Membrane Science 415-416, 1-8.

491 Shannon, M.A., Bohn, P.W., Elimelech, M., Georgiadis, J.G., Marinas, B.J. and Mayes, A.M. 492 (2008) Science and technology for water purification in the coming decades. Nature 493 452(7185), 301-310. 
494 Snyder, S.A., Westerhoff, P., Yoon, Y. and Sedlak, D.L. (2003 ) Pharmaceuticals, Personal 495 Care Products, and Endocrine Disruptors in Water: Implications for the Water Industry. 496 Environmental Engineering Science 20(5), 449-469.

497 Sutzkover, I., Hasson, D. and Semiat, R. (2000) Simple technique for measuring the 498 concentration polarization level in a reverse osmosis system. Desalination 131(1-3), 117-127.

499 Tiraferri, A. and Elimelech, M. (2012) Direct quantification of negatively charged functional 500 groups on membrane surfaces. Journal of Membrane Science 389, 499-508.

501 Tiraferri, A., Yip, N.Y., Phillip, W.A., Schiffman, J.D. and Elimelech, M. (2011) Relating 502 performance of thin-film composite forward osmosis membranes to support layer formation 503 and structure. Journal of Membrane Science 367(1-2), 340-352.

504 Valladares Linares, R., Yangali-Quintanilla, V., Li, Z. and Amy, G. (2011) Rejection of 505 micropollutants by clean and fouled forward osmosis membrane. Water Research 45(20), $506 \quad 6737-6744$.

507 Wang, R., Shi, L., Tang, C.Y., Chou, S., Qiu, C. and Fane, A.G. (2010) Characterization of 508 novel forward osmosis hollow fiber membranes. Journal of Membrane Science 355(1-2), 509 158-167.

510 Wei, J., Qiu, C., Tang, C.Y., Wang, R. and Fane, A.G. (2011) Synthesis and characterization 511 of flat-sheet thin film composite forward osmosis membranes. Journal of Membrane Science 512 372(1-2), 292-302.

513 Wilke, C.R. and Chang, P. (1955) Correlation of diffusion coefficients in dilute solutions. 514 AIChE Journal 1(2), 264-270.

515 Xie, M., Nghiem, L.D., Price, W.E. and Elimelech, M. (2012a) Comparison of the removal of 516 hydrophobic trace organic contaminants by forward osmosis and reverse osmosis. Water 517 Research 46(8), 2683-2692.

518 Xie, M., Price, W.E. and Nghiem, L.D. (2012b) Rejection of pharmaceutically active 519 compounds by forward osmosis: Role of solution $\mathrm{pH}$ and membrane orientation. Separation 520 and Purification Technology 93, 107-114.

521 Xie, M., Price, W.E., Nghiem, L.D. and Elimelech, M. (2013) Effects of feed and draw 522 solution temperature and transmembrane temperature difference on the rejection of trace 523 organic contaminants by forward osmosis. Journal of Membrane Science 438, 57-64.

524 Yangali-Quintanilla, V., Li, Z., Valladares, R., Li, Q. and Amy, G. (2011) Indirect 525 desalination of Red Sea water with forward osmosis and low pressure reverse osmosis for 526 water reuse. Desalination 280(1-3), 160-166.

527 Yip, N.Y., Tiraferri, A., Phillip, W.A., Schiffman, J.D. and Elimelech, M. (2010) High 528 Performance Thin-Film Composite Forward Osmosis Membrane. Environmental Science \& 529 Technology 44(10), 3812-3818.

530 Yong, J.S., Phillip, W.A. and Elimelech, M. (2012) Coupled reverse draw solute permeation 531 and water flux in forward osmosis with neutral draw solutes. Journal of Membrane Science 532 392-393, 9-17.

533 Zhao, S., Zou, L., Tang, C.Y. and Mulcahy, D. (2012) Recent developments in forward 534 osmosis: Opportunities and challenges. Journal of Membrane Science 396, 1-21. 